International Journal of Fuzzy Logic Systems (IJFLS) Vol.6, No.1, January 2016

\title{
FUZZY LOAD FREQUENCY CONTROLLER IN DEREgulated PoWER ENVIRONMENT BY PrinCIPAL COMPONENT ANALYSIS
}

\author{
S.Srikanth ${ }^{1}$, K.R.Sudha ${ }^{2}$ And Y.Butchi Raju ${ }^{3}$ \\ ${ }^{1}$ Professor, Dept. of Electrical Engg., B.V.C.Engineering College, A.P, India. \\ ${ }^{2}$ Professor, Dept. of Electrical Engg., Andhra University(W), Visakhapatnam, India. \\ ${ }^{3}$ Assoc. Professor, E.E.E. Dept, Sir. C.R. R. College, A.P, India.
}

\begin{abstract}
Deregulated Load Frequency Control (DLFC) plays an important role in power systems. The main aim of DLFC is to minimize the deviation in area frequency and tie-line power changes. Conventional PID controller gains are optimally tuned at one operating condition. The main problem of this controller is that it fails to operate under different dynamic operating conditions. To overcome that drawback, fuzzy controllers have very much importance. The design of Fuzzy controller's mostly depends on the Membership Functions (MF) and rule-base over the input and output ranges controllers. Many methods were proposed to generate and minimize the fuzzy rules-base. The present paper proposes an optimal fuzzy rule base based on Principal component analysis and the designed controller is tested on three area deregulated interconnected thermal power system. The efficacies of the proposed controller are compared with the Fuzzy C-Means controller and Conventional PID controller.
\end{abstract}

\section{KEYWORDS}

Deregulated Load Frequency Control (DLFC), PID Controller, Fuzzy PID Controller (FPID), Fuzzy Cmeans Controller (FCM), Fuzzy Principal component analysis controller (FPCA)

\section{INTRODUCTION}

A power system with deregulated load frequency control may consist of Distribution companies (DISCOMS), Transmission companies (TRANSCOS) and Generation companies (GENCOS). There is a basic difference between the AGC operation in conventional and deregulation power system $[1,16]$. After deregulation the vertically integrated utilities (VIU) that own the electrical power generation, transmission and distribution companies amenities provide power at minimum cost to the consumers, after restructuring processes Generation companies (GENCOS), Transmission companies (TRANSCOS), Distribution companies (DISCOMs) and Independent system operators (ISO) are introduced competition in power system[2,3]. Alternative to select among DISCOMs in their won area, while DISCOMs of an area have the choice to have power contracts for transaction of power with GENCOs of the same or other area[5,17].

DOI : $10.5121 /$ ijfls.2016.6102 
International Journal of Fuzzy Logic Systems (IJFLS) Vol.6, No.1, January 2016

Research on the DLFC problem shows that the Fuzzy Proportional Integral Derivative (FPID) controller has been proposed to enhance the performance of deregulated power system load frequency control $[10,11]$.

The design of a Fuzzy Clustering means (FCM) controller required rule-base from the phase-plane plots of the inputs given to the fuzzy controller. The 'closed-loop' trajectory is mapping on position space of the inputs. The clusters are shaped in complete position space of the inputs using Fuzzy C-means. The cluster centers are identified and marked on the phase-plane plot. These are mapping by the 'closed-loop trajectory'. Hence the necessary rules are recognized and the 'non-cooperative rules' are eliminated.

The major disadvantage is Fuzzy C-Means algorithm only detects the data classes with the same super spherical shapes. To overcome the above demerit, a new algorithm is developed fuzzy Principal component analysis (FPCA) involve a geometric procedure that 'transforms' a number of correlated variables in to a number of 'uncorrelated variables' are called 'principal components' [5, 18]. The proposed Fuzzy Principal component analysis Clustering controller with reduced rule base is compared to FCM and Fuzzy PID controller. The above controller test in a three area deregulated load frequency control.

\section{Modeling Of Three Area load Frequency Control In Deregulated PoWer System}

The three area load frequency control in deregulated power system environment consists of three power system areas, each power system area with two thermal plants and two DISCOMs as shown in Fig.1. The detailed schematic diagram of three area deregulated power system six GENCO with six DISCOMs as shown in Fig.2.

In the open market purchases, any GENCO in one area may supply its DISCOMs and DISCOMs in other two areas through tie-lines allowing power transfer between all three power system areas. In a deregulated power system having several GENCOS and DISCOMs, any DISCOM may contract with any GENCO in another control area independently, is known as mutual transaction [18]. These transactions are to be carried out through an independent system operator (ISO).

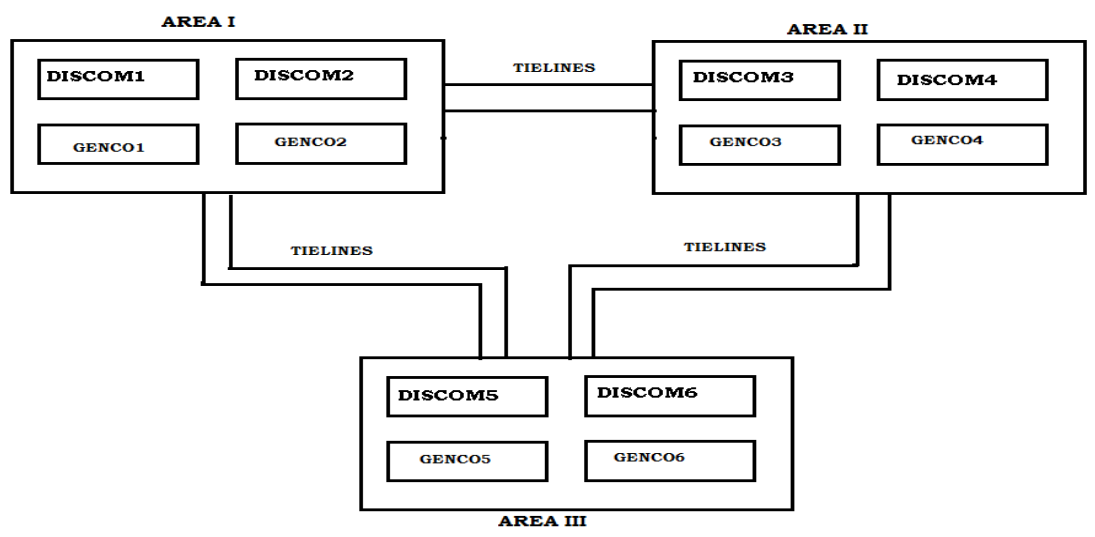

Figure.1. Three area load frequency in deregulated power system 
The main purpose of ISO is to control system operator in all GENCOs and DISCOMs, like Automatic Generation Control. Any DISCOM in a deregulated environment will have the free to purchase power at competitive price from different GENCOs, which can or cannot have contract with the won area when the 'DISCOM' [9]. In the present paper for the load frequency control GENCO-DISCOM contracts are represented with 'DISCOM participation matrix' (DPM). DPM effectively provides the participation of a DISCOM in contract with a GENCO. The concept of 'DISCOM Participation Matrix' (DPM) is used to express the possible contracts . The number of rows and columns of DPM matrix is equal to the total number of GENCOs and DISCOMs in the overall power system, respectively. Each element of the DPM is a fraction of total load power contracted by a DISCOM from a GENCO and is called a contract participation factor ( cpf). The total of all the elements in a column in 'DPM' is unity.

$$
\mathrm{DPM}=\left[\begin{array}{llllll}
\mathrm{cpf}_{11} & \mathrm{cpf}_{12} & \mathrm{cpf}_{13} & \mathrm{cpf}_{14} & \mathrm{cpf}_{15} & \mathrm{cpf}_{16} \\
\mathrm{cpf}_{21} & \mathrm{cpf}_{22} & \mathrm{cpf}_{23} & \mathrm{cpf}_{24} & \mathrm{cpf}_{25} & \mathrm{cpf}_{26} \\
\mathrm{cpf}_{31} & \mathrm{cpf}_{32} & \mathrm{cpf}_{33} & \mathrm{cpf}_{34} & \mathrm{cpf}_{35} & \mathrm{cpf}_{36} \\
\mathrm{cpf}_{41} & \mathrm{cpf}_{42} & \mathrm{cpf}_{43} & \mathrm{cpf}_{44} & \mathrm{cpf}_{45} & \mathrm{cpf}_{46} \\
\mathrm{cpf}_{61} & \mathrm{cpf}_{62} & \mathrm{cpf}_{63} & \mathrm{cpf}_{54} & \mathrm{cpf}_{55} & \mathrm{cpf}_{56} \\
\mathrm{cpf}_{65} & \mathrm{cpf}_{66}
\end{array}\right]
$$

Where $\quad \operatorname{cpf}_{\mathrm{ij}}=\frac{\mathrm{j}^{\text {th }} \text { DISCO power demand out of } \mathrm{i}^{\text {th }} \text { GENCOin p.uMW }}{\mathrm{j}^{\text {th }} \text { DISCO total power demand in p.uMW }}$

Whenever a load demanded by a DISCOM1 changes, it is observed as a local load change in the area1, which is similar with other areas corresponds to the local loads $\Delta \mathrm{P}_{\mathrm{D} 1}, \Delta \mathrm{P}_{\mathrm{D} 2}, \Delta \mathrm{P}_{\mathrm{D} 3}$. This should be reflected in the block diagram of three area power system in deregulated environment at the point of input to the power system block. Each area two GENCOs, 'Area Control Error' (ACE) signal has to be "distributed" among them. The factor that distributes "ACE participation factors' (apf)

Therefore

$$
\sum_{K=1}^{n} a_{p f k}=1
$$

Where total number of 'plants' are $\mathrm{n}$

The each 'particular' set of 'GENCOs' are invented to follow the 'load demanded' by a DISCOM, the demand signals must flow from a DISCOM to a particular GENCO specifying 'corresponding' load demands. These signals which are absent in traditional AGC system describes the partial demands and are specified by the cpfs and the per unit MW load of a DISCOM. The signals take information as to which plants have to track a 'load demanded' by which 'DISCOM'. In the present case of three areas, the scheduled steady state power flow on the tie-line is given as in (4) and the tie line power error is expressed as in (5) which is used to generate the area control error (ACE) . For n-number power system areas, Area Control Error in $\mathrm{i}^{\text {th }}$ area is given in (6) 
International Journal of Fuzzy Logic Systems (IJFLS) Vol.6, No.1, January 2016

$\Delta \mathrm{P}_{\text {tieij }}($ scheduled $)=$

(demand of DISCO in $\mathrm{j}^{\text {th }}$ area from GENCO in $\mathrm{i}^{\text {th }}$ area)

- (demand of DISCO in $\mathrm{i}^{\text {th }}$ area from GENCO in $\mathrm{j}^{\text {th }}$ area $)$

$\Delta \mathrm{P}_{\text {tie ij }}($ error $)=\Delta \mathrm{P}_{\text {tieij }}($ actual $)-\Delta \mathrm{P}_{\text {tie ij }}($ scheduled $)$

The traditional scenario 'error signal' is use to make the respective 'ACE signals' as in the.

$\mathrm{ACE}=\mathrm{B} \Delta \mathrm{f}+\Delta \mathrm{P}_{\text {tie error }}$

(6)

For our case

NGENCO $=6=$ Total number of generation companies

NDISCO $=6=$ Total number of distribution companies

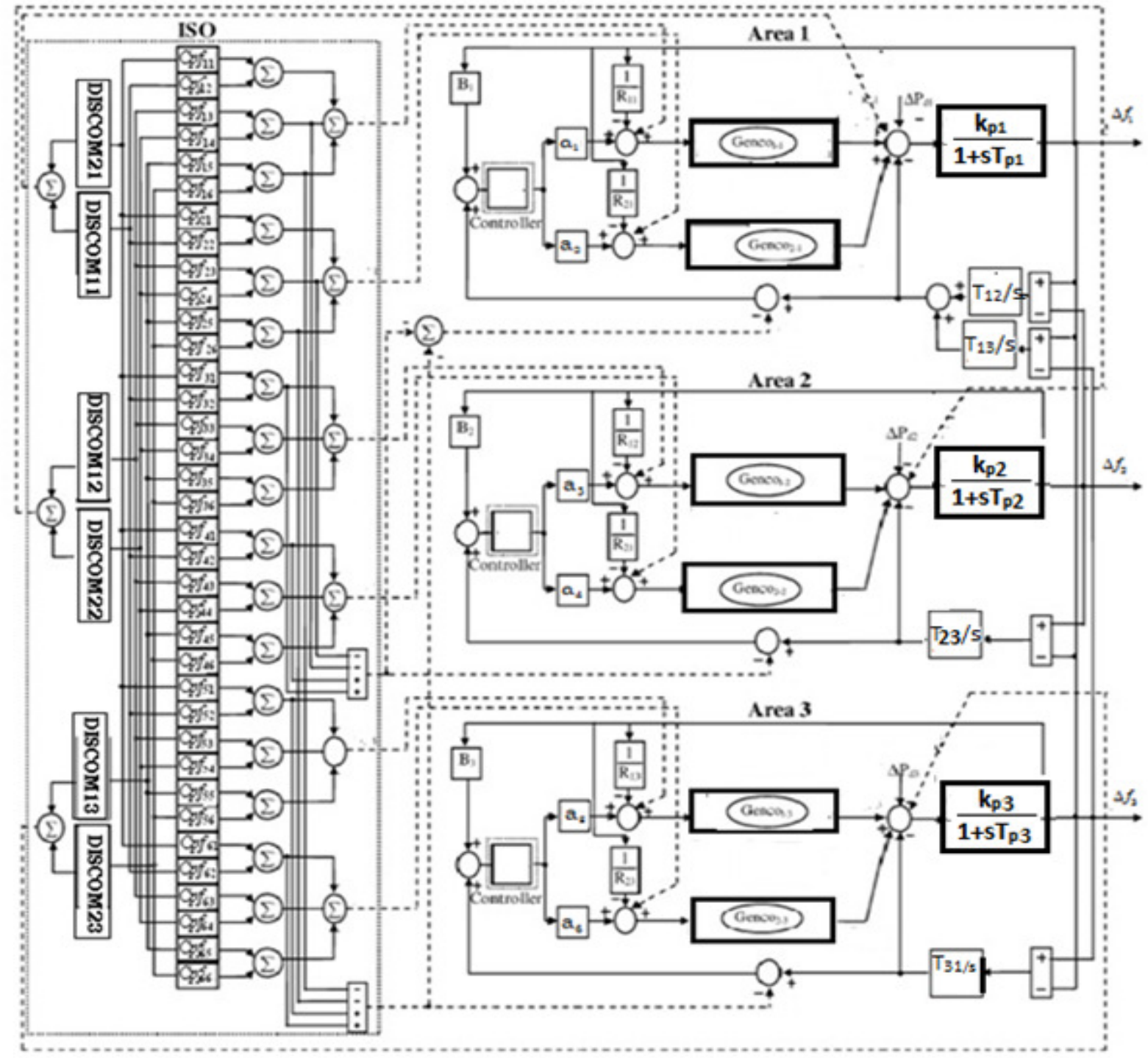

Figure.2. Three area deregulated LFC 


\section{Design Of Fuzzy Logic PID (FPID) Controller}

The general model of Fuzzy PID normal Controller and it mainly four important components are Fuzzification module, Inference mechanism, Knowledge base and defuzzification module.

\subsection{Fuzzification Module:}

In primary operation is import is fuzzification which include convert all the range of input data with output of the FLC their corresponding data $[12,13]$. The next performance procedure is dividing the respective input keen on suitable linguistic variables these variables in fuzzification module depend on triangle shape of the Membership functions (MF).

\subsection{Fuzzy Inference mechanism:}

Interface mechanism plays a important role in designing FLC. The membership functions obtained in first step are combined to acquire the firing strength of individual rule [24, 25]. Each rule characterizes the control goal and control strategy of the field experts by means of a set of Fuzzy control rules $[8,14]$. Then depending on firing strength, the consequent part of each qualified rule is generated.

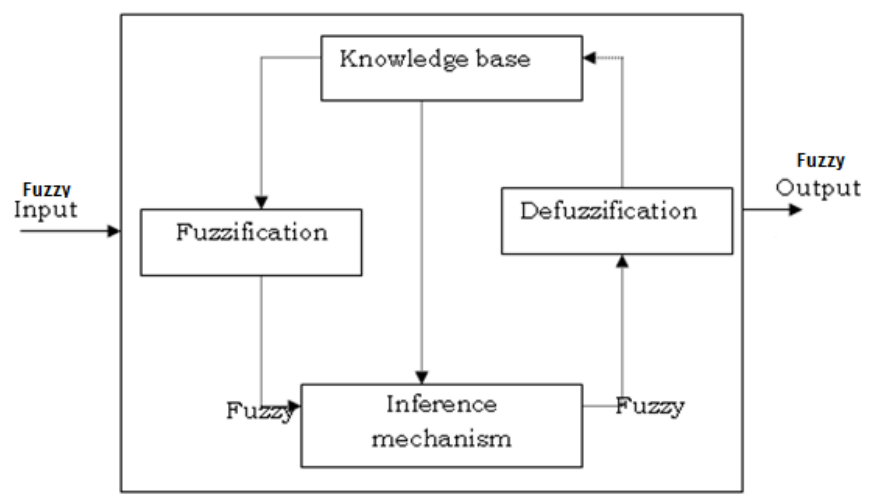

Figure.3. Basic model of FPID controller

\subsection{Knowledge base:}

The knowledge base of an FLC consists of a database, whose basic function is to provide, the necessary information for the proper functioning of the 'fuzzification module', the inference engine and the 'de-fuzzification module'. The necessary information includes:

a) 'Fuzzy membership' representing the meaning of the 'linguistic variables' of the process status and the 'control output variables'.

b) Physical domains and their normalized counter-parts together with the normalization (scaling) factors. 


\subsection{Defuzzification module:}

The following are the functions of the Defuzzification module:

a) It converts the set of modified control output values into a non-fuzzy control output.

b) It performs an output de-normalization which maps the range of values of fuzzy sets to the normal area

The commonly used strategies for defuzzification are (i) max criterion (ii) the mean of maximum and (iii) the center of areas. Approach generates the 'center of gravity' of the opportunity distribution of a 'control action'.

$\mathrm{U}=\frac{\sum\{\text { Membership value of input } \times \text { output corresponding to the membership value of input }\}}{\sum\{\text { membership value of input }\}}$

$\mathrm{U}=\frac{\sum v(\mathrm{Ai}, \mathrm{Bi})}{\sum \mu(\mathrm{Ai}, \mathrm{Bi})}$

\subsection{Design of three input MF FPID Controller:}

Design of FPID Controller similar to PID controller as below fig 4.

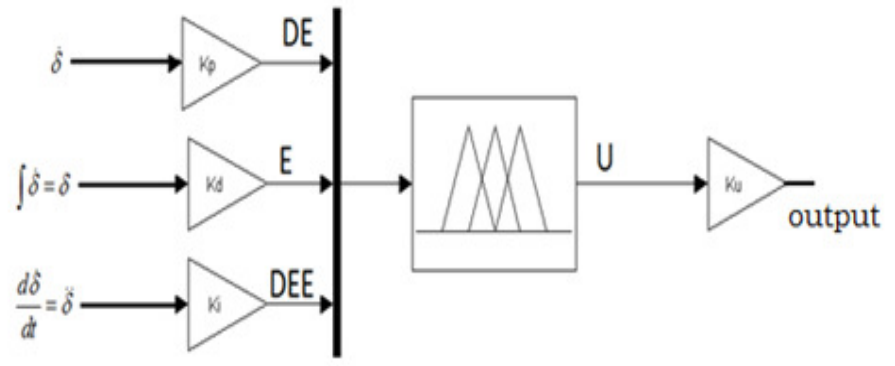

Figure.4.basic model FPID controller

Three variables $\delta, \dot{\delta}, \ddot{\delta}$ are used as input signals. The coefficients $\mathrm{K}_{\mathrm{p}}, \mathrm{K}_{\mathrm{d}}, \mathrm{K}_{\mathrm{i}}$ which are called Fuzzy variables, transform the scaled real values to required values in decision limit. The 'output signal' $\mathrm{K}_{\mathrm{u}}$ is inject to the 'summing point'. The normalized inputs of the proposed controllers namely DE, E, and DEE are equal to $\mathrm{K}_{\mathrm{p}} \dot{\delta}, \mathrm{K}_{\mathrm{i}} \delta, \mathrm{K}_{\mathrm{d}} \ddot{\delta}$ respectively. The three similar fuzzy sets defining the three inputs of the proposed FLCPID controller are given by equation (8). The inputs of the fuzzy sets considered are shown in figure .5 and the MF of these are defined by $\mu_{\mathrm{p}}(),. \mu_{\mathrm{N}}($.$) hand \mu_{\mathrm{Z}}($.$) or \mu_{1}(.) \mu_{-1}($.$) and \mu_{0}($.

$$
\mathrm{K}_{\mathrm{p}} \dot{\delta}=\mathrm{K}_{\mathrm{d}} \ddot{\delta}=\mathrm{K}_{\mathrm{i}} \delta=\{\mathrm{N}(\text { Negative }), \mathrm{Z}(\text { Zero }), \mathrm{P}(\text { Positive })\}
$$


International Journal of Fuzzy Logic Systems (IJFLS) Vol.6, No.1, January 2016

Let the number of linguistic variables and their values are the inputs and their MF is identical. If the members of the input fuzzy set $\mathrm{N}, \mathrm{Z}$ and $\mathrm{P}$ are $\mathrm{X}_{-1}(),. \mathrm{X}_{0}(),. \mathrm{X}_{1}($.$) respectively, then the$ output function is derived using the following control rules, where $\mathrm{i}, \mathrm{j}$ and $\mathrm{k}$ can take any value from $(-1,0,+1)$.

IF DE is $\mathrm{x}_{\mathrm{i}}$ and $E$ is $\mathrm{x}_{\mathrm{j}}$ and DEE is $\mathrm{x}_{\mathrm{k}}$ THEN output is $\mathrm{U}_{-(\mathrm{i}+\mathrm{j}+\mathrm{k})}$

The above fuzzy rule is called a linear control rule because the linear function is employed to relate the indices of the input fuzzy variables sets to the index of the linguistic variables output fuzzy set. Based on this concept the rules framed.

\subsection{FPID Controller Rules}

FPID control rules are linear, the number of 'membership functions' of the fuzzy output place will be equal to $(3 \mathrm{~N}-2)$ for $\mathrm{N} \geq 3$, The number of membership functions $\mathrm{N}$ of each input. In the proposed case $\mathrm{N}=3$, hence the output fuzzy set has seven membership functions defined as follows:

$$
\mathrm{U}=\left\{\begin{array}{c}
N B(\text { negative big }), N M(\text { negative medium }), N S(\text { negative small }) \\
Z(\text { zero }) \\
P B(\text { positive big }), P S(\text { positive small }), P M(\text { positive medium })
\end{array}\right.
$$

The triangular membership functions as in Fig (5) are considered and partitioned within the UOD in the range $[-1,+1]$ for the outputs. The mathematical model of membership function is given as follows

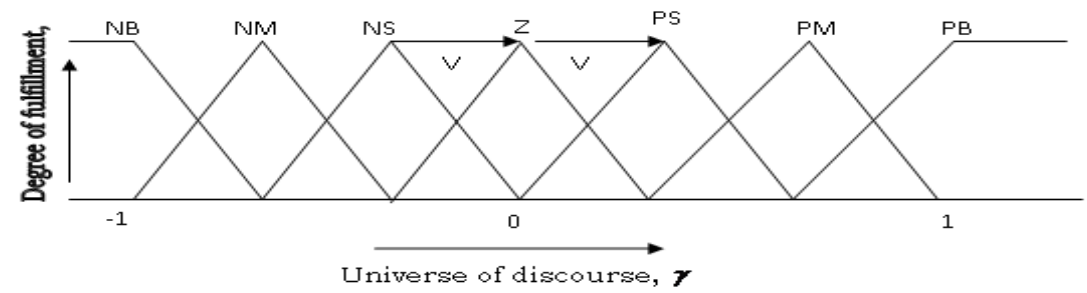

Figure.5. Membership-Functions Outputs

The portion of the 'Membership-Functions' output should be symmetrical about its essential value and the 'shape' of every the members of 'Membership-Functions' should be same $[14,20]$. The decisions in fuzzy logic based approach are made by forming series of rules which relate the inputs to outputs by IF-THEN statements [21]. In this case the number of control rules to cover all the possible combinations of the three membership functions of each input variable is $3 \times 3 \times 3(27)(4)$. These rules are composed as below table1. 
International Journal of Fuzzy Logic Systems (IJFLS) Vol.6, No.1, January 2016

Table 1.27 Rules for three input member ship functions

\begin{tabular}{|l|l|l|l|l|l|l|l|l|l|}
\hline Rule & DEE & DE & E & Out put & Rule & DEE & DE & E & Out put \\
\hline 1 & P & P & P & NB & 15 & N & Z & N & PM \\
\hline 2 & P & P & Z & NM & 16 & N & N & P & PS \\
\hline 3 & P & P & N & NS & 17 & N & N & Z & PM \\
\hline 4 & P & Z & P & NM & 18 & N & N & N & PB \\
\hline 5 & P & Z & Z & NS & 19 & Z & P & P & NM \\
\hline 6 & P & Z & N & Z & 20 & Z & P & Z & NS \\
\hline 7 & P & N & P & NM & 21 & Z & P & N & Z \\
\hline 8 & P & N & Z & Z & 22 & Z & Z & P & NS \\
\hline 9 & P & N & N & PS & 23 & Z & Z & Z & Z \\
\hline 10 & N & P & P & NS & 24 & Z & Z & N & PS \\
\hline 11 & N & P & Z & Z & 25 & Z & N & P & Z \\
\hline 12 & N & P & N & PS & 26 & Z & N & Z & PS \\
\hline 13 & N & Z & P & Z & & & & & \multirow{2}{*}{ PM } \\
\hline 14 & N & Z & Z & PS & 27 & Z & N & N & PM \\
\hline
\end{tabular}

\section{Design Of FCM CONTROLler}

Fuzzy control normal system requires characterization of the relation between state spaces and the rules associated with the transient system under control this relation is based on the relative influence of every rule of the rule base on the direct action produced by 'fuzzy inference engine' [6].

A closed loop trajectory can be mapped on the position space [19]. Linguistic trajectory is formed by the series of rules obtained 'according' to the arrange in which they are fired forms. This corresponds to a certain system trajectory [22]. This provides strategy to attain the necessary rulebase starting the 'phase-plane' plots of the inputs given to the fuzzy controller [23]. The space of the inputs is mapped on position 'closed-loop trajectory'. The formed clusters are in complete location space of the inputs using Fuzzy C-means. The cluster centers are recognized and marked on the phase-plane plot. The closed-loop 'trajectory' with these is mapped. Hence the 'noncooperative' rules are deleted and the necessary rules are identified.

\subsection{Design procedure for FCM Controller}

1) The Fuzzy controller is designed normally with 27 rules

2) The 'Fuzzy C-Means controller's' is tuned to the same as fuzzy controller.

3) From the input space of fuzzy controller the 'phase-plane' plot is obtained.

4) FCM algorithm using input space is 'divided' in to 'clusters' and the centers of 'cluster' are recognized.

5) The series of rules of the normal 'fuzzy controller' is great imposed onto the 'phase-plane' plot of the 'input space' with 'cluster centers' below fig.6.

6) Hence the 'non-cooperative' rules are deleted and the necessary rules are 'identified' below table2. 


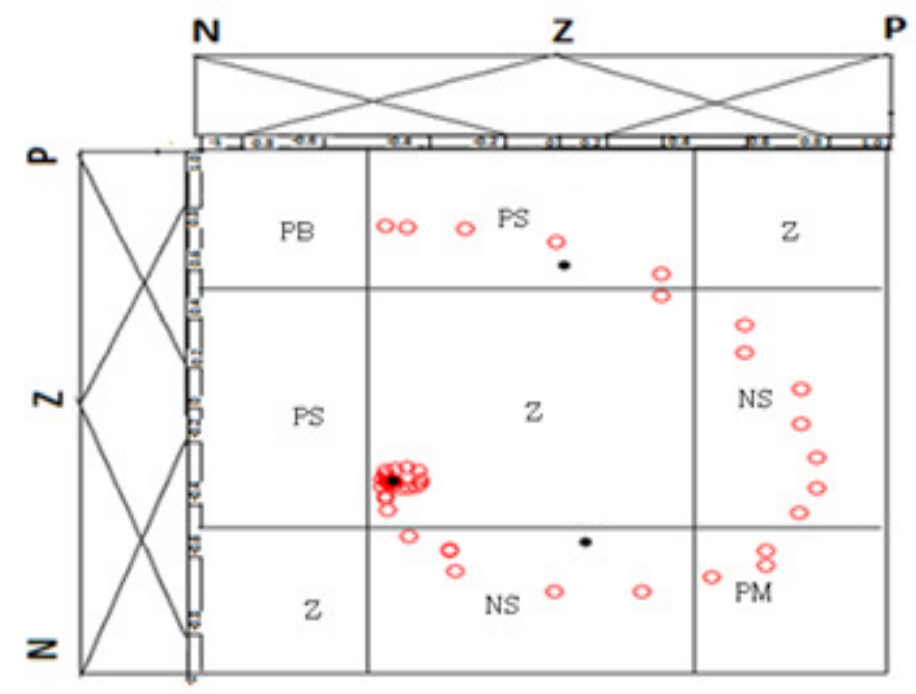

Fig.6. phase plane plot to identify required rules

Table.2. Rules for three -input member ship functions for FCM Controller

\begin{tabular}{|l|l|l|l|l|}
\hline Rule & DEE & E & DE & Out put \\
\hline 26 & Z & Z & N & PS \\
\hline 23 & Z & Z & Z & Z \\
\hline 20 & Z & Z & P & NS \\
\hline
\end{tabular}

\section{Design Of Fuzzy Principal Component Analysis (FPCa) CONTROLLER}

The major disadvantage is Fuzzy C-Means algorithm only detects the data classes with the same super spherical shapes. To overcome the above demerit new algorithm is developed fuzzy Principal component analysis (FPCA) involves a mathematical procedure that transforms a number of (possibly) correlated variables in to a (smaller) number of uncorrelated variables are called principal components [5]. The first principal component accounts for as much of the variability in the data as possible and each succeeding component accounts for as much of the remaining variability as possible [10]. The main objectives of FPCA are:

1) New meaningful fundamental variables Identify

2) Determine or to decrease the 'dimensionality' of the data set

3) The protrusion of correlated 'high-dimensional' data onto a 'hyper-plane'

There are several equivalent ways of deriving the principal components mathematically. The 'simplest' one is by discovery the 'projections' which large the 'variance' [11]. The initial 'principal component' is the path in quality space along which 'projections' have the biggest variance. The next 'principal component' is the path which large 'variance' among all 'directions' orthogonal to the initial. The $\mathrm{n}^{\text {th }}$ element is the 'variance-maximizing' direction 'orthogonal' to the before ( $\mathrm{n}-1)$ components. There are $\mathrm{p}$ principal components in all. Relatively 
than large variance, it power sound more promising to appear for the 'projection' with the least regular ('mean-squared') distance between the innovative 'vectors' and their 'projections' on to the 'principal components'. This twist out to be corresponding to large the variance. Which the data points are projected and data is clustered with PCA algorithm indentifies minimum number of contributed rules.

\subsection{Proposed FPCA Algorithm:}

1) The common Fuzzy controller is designed normally with 27 rules

2) The 'FPCA controller' is tuned to the same as 'fuzzy controller'.

3) It is the best possible linear design for 'compressing' a set of large 'dimensional' vectors into a set of lesser 'dimensional' vectors and then reconstructing

4) Form the matrix of squares and products of the features $Z^{T} Z$, where scaled report of the 'matrix' $\mathrm{X} \& \mathrm{Z}$ is the 'centered'.

5) The next 'principal component' is the direction 'orthogonal' to the initial component with the large variance. Since it is 'orthogonal' to the initial 'eigenvector', their 'projections' resolve be 'uncorrelated' and the 'principal components' are 'uncorrelated' with all other 6) The 'principal components' are designed as $\mathrm{P}=\mathrm{XE}$, where $\mathrm{X}$ is the 'original data matrix' of order $\mathrm{n} \times \mathrm{j}$, of 'principal components' $\mathrm{P} 1, \mathrm{P} 2, \mathrm{P} 3, \mathrm{P} 4 \ldots$

7) The input space is divided into Principal components using PCA and the Principle components are identified using fig.7.

8) The sequence of rules of the unusual fuzzy controller is recognized by using 'Principal components'.

9 Hence the 'non-cooperative' rules are deleted and the necessary rules are 'identified' below table3.

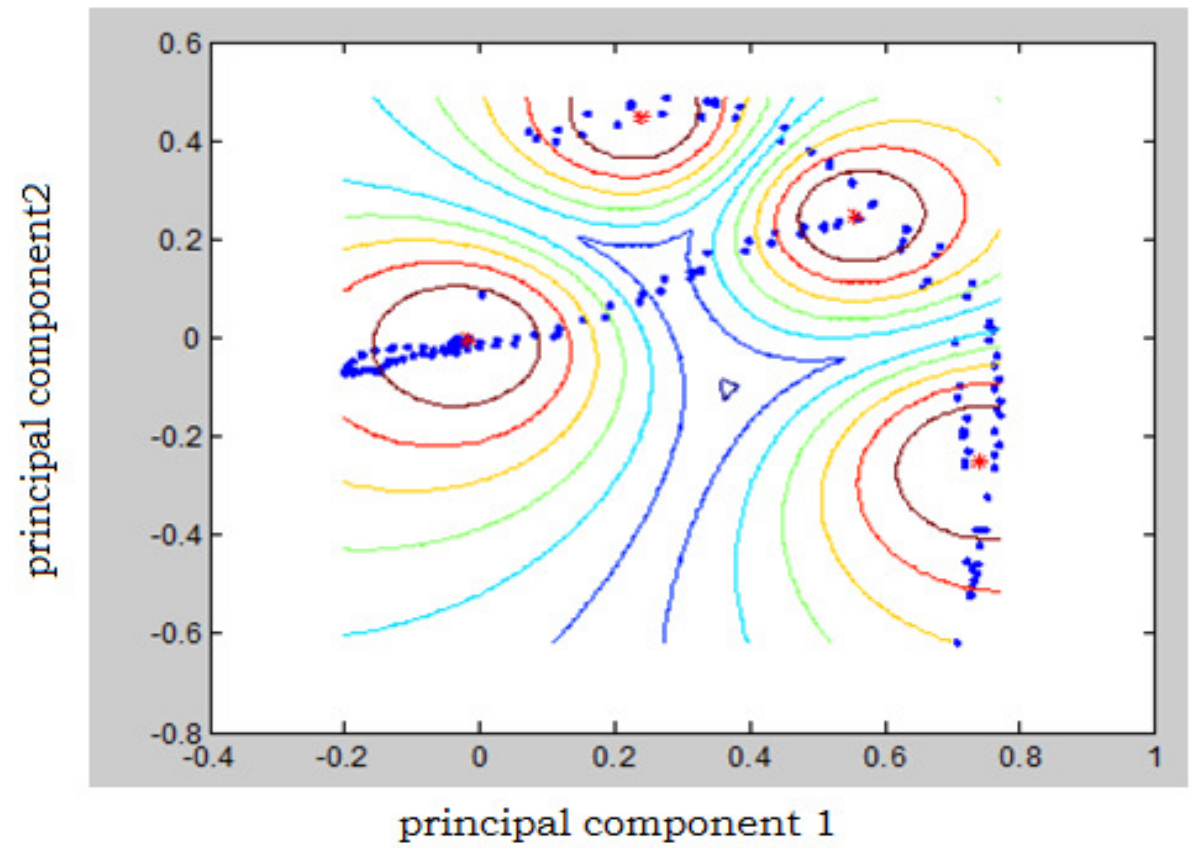

Figure 7.Clusters using principal component analysis 
International Journal of Fuzzy Logic Systems (IJFLS) Vol.6, No.1, January 2016

Table.3. Rules for three-input member ship functions for FPCA Controller

\begin{tabular}{|l|l|l|l|l|}
\hline Rule & DEE & DE & E & Out put \\
\hline 20 & Z & P & Z & NS \\
\hline 22 & Z & Z & P & NS \\
\hline 23 & Z & Z & Z & Z \\
\hline 26 & Z & N & Z & PS \\
\hline
\end{tabular}

\section{ReSults AND Discussions}

The robustness and efficacy of the proposed FPCA controller with minimum rule base is tested three-area inter connected deregulated power environment for various operating conditions and are compared with performance of FCM and PID controller.

Case1: In this case each GENCO in each control area participates in AGC, with area participation factors apf1-apf6 as defined by following:

apf $1=0.5, \operatorname{apf} 2=1-\operatorname{apf} 1=0.5, \operatorname{apf} 3=0.5$, apf $4=1-\operatorname{apf} 3=0.5$, apf5 $=0.6$, apf6 $=1-$ apf5 $=0.4$,

Consider that all the DISCOMs contract with the GENCOs for power as per the below DPM. Suppose that DISCOM3 demands 0.1PU MW power, out of which 0.05PU MW is demanded 0.015PU MW is demanded from GENCO2, 0.02PU MW from GENCO4, and 0.015PU MW from GENCO5. DISCOM3 does not demand any per unit MW from GENCO1, GENCO3, and GENCO6. Then row 2 entries in DPM are easily defined as

$$
\begin{gathered}
c p f_{31}=c p f_{33}=c p f_{36}=0, c p f_{32}=\frac{0.015}{0.1}=0.15, c p f_{34}=c p f_{35}=\frac{0.02}{0.1}=0.2 \\
D P M=\left[\begin{array}{cccccc}
0.3 & 0.25 & 0 & 0.4 & 0.1 & 0.6 \\
0.2 & 0.15 & 0 & 0.2 & 0.1 & 0 \\
0 & 0.15 & 0 & 0.2 & 0.2 & 0 \\
0.2 & 0.15 & 1 & 0 & 0.2 & 0.4 \\
0.2 & 0.15 & 0 & 0.2 & 0.2 & 0 \\
0.1 & 0.15 & 0 & 0 & 0.2 & 0
\end{array}\right]
\end{gathered}
$$

Step increase in load demand in all three areas $\triangle \mathrm{PD} 1, \Delta \mathrm{PD} 2$, and $\triangle \mathrm{PD} 3$ is applied in this case. The frequency deviation in area1 $(\Delta \mathrm{f} 1)$ is shown in Fig.8, frequency deviation in area2 $(\Delta \mathrm{f} 2)$ is shown in Fig.9, and frequency deviation in area3 $(\Delta \mathrm{f} 3)$ is shown in Fig.10. It can be observed that the proposed FPCA controller with minimum rule base has better performance in all responses with respect to overshoot, undershoot and settling time and robustness when compared to FCM controller and PID controller. 
International Journal of Fuzzy Logic Systems (IJFLS) Vol.6, No.1, January 2016

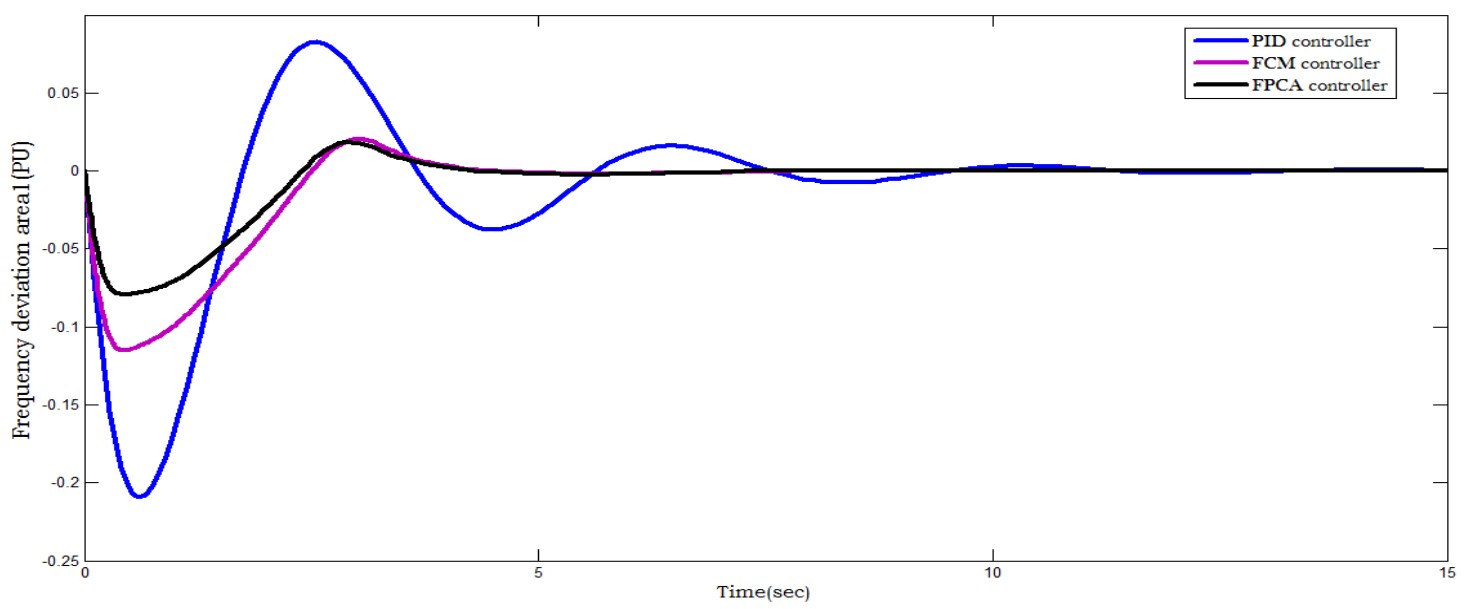

Figure8. Frequency deviation in area 1 with step increase in $\Delta \mathrm{PD} 1, \Delta \mathrm{PD} 2$ and $\Delta \mathrm{PD} 3$

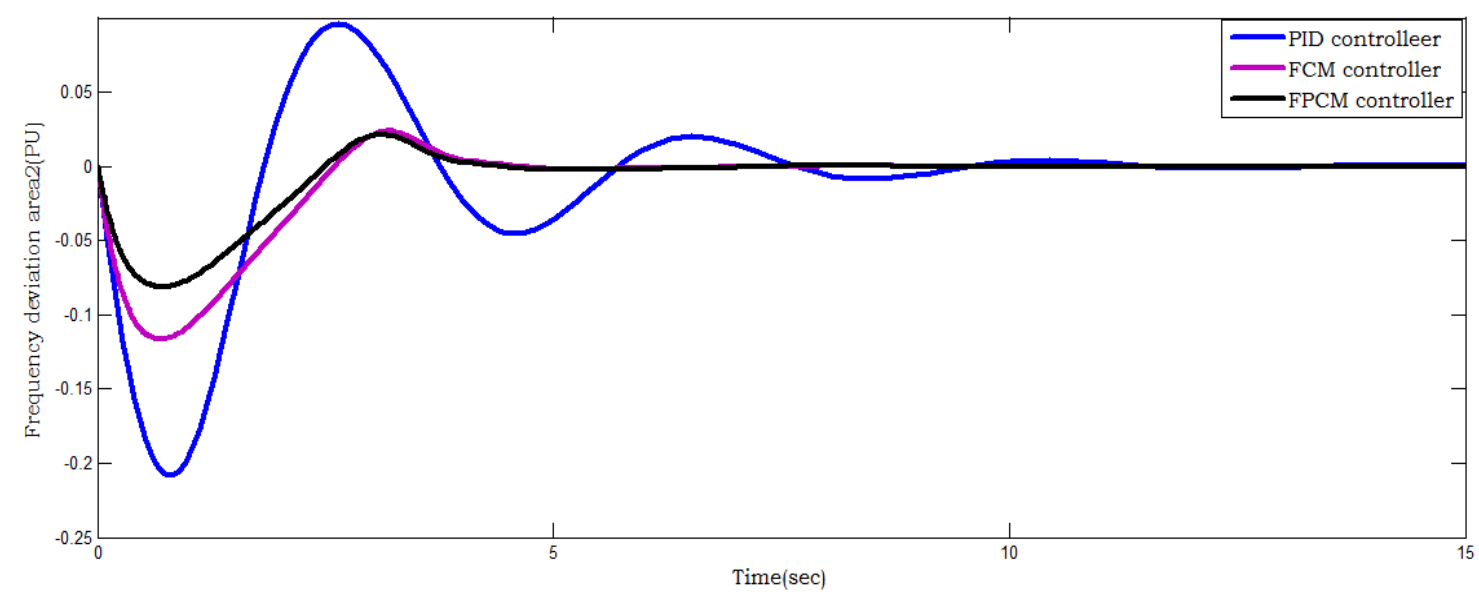

Figure 9.Frequency deviation in area 2 with step increase in $\Delta \mathrm{PD} 1, \Delta \mathrm{PD} 2$ and $\Delta \mathrm{PD} 3$

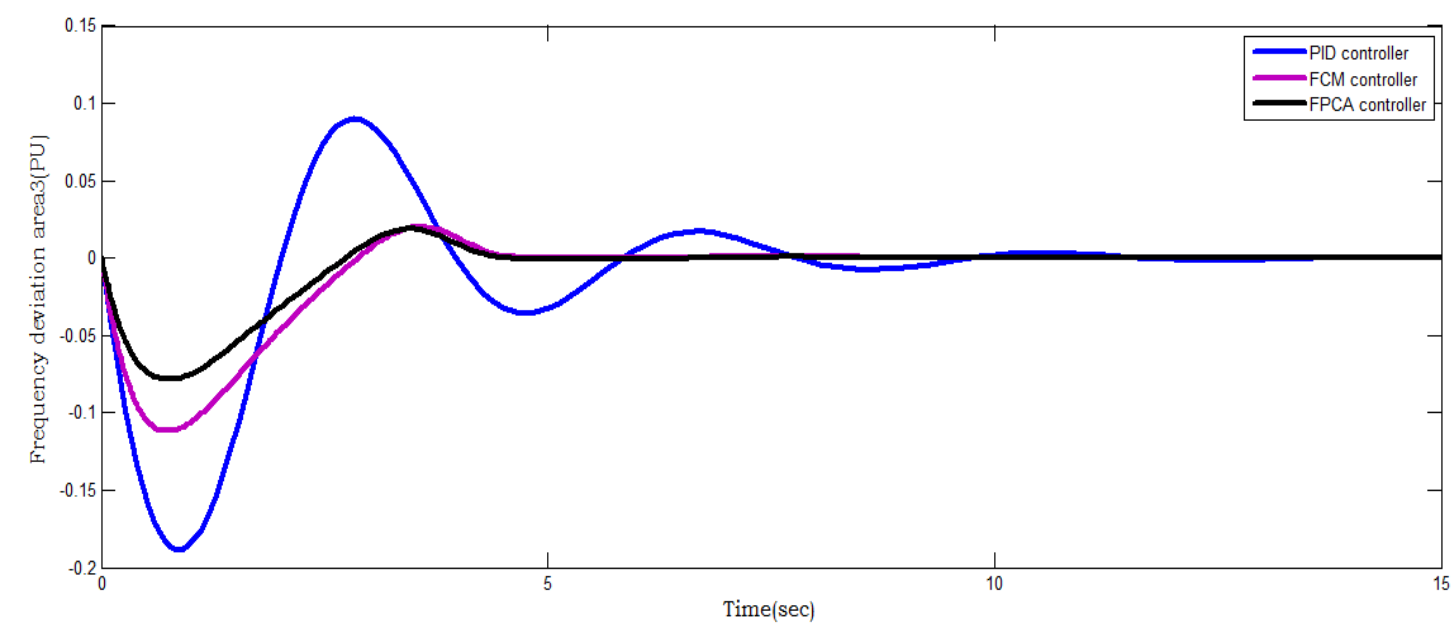

Fig.10.Frequency deviation in area 3 with step increase in $\Delta \mathrm{PD} 1, \Delta \mathrm{PD} 2$ and $\Delta \mathrm{PD} 3$ 


\section{Case2:}

In this case same as the case 1 but included the Generator Rate Constraints (GRC) the rate of change in the power generating is to be maintained at a specified maximum limit. In regulate to consider effect of the GRC into account a step load disturbance of $1 \%$ in area 1, area2 and area 3 , the MATLAB simulation power system model of a non reheating turbine is changed through a nonlinear model of Fig.11 with saturation element $d= \pm 0.1$ P.U/minute is considered. For the present test system, the generating rate constraints is set to \pm 0.1 by using each limiters in each GENCO within the AGC controller to provide the control action within set limits. It can be observed that the proposed FPCA controller with minimum rule base has better performance in all responses with respect to overshoot, undershoot and settling time and robustness when compared to FCM controller and PID controller are tested deregulated power system with including GRC. The outcome in above case are given in Fig12-14

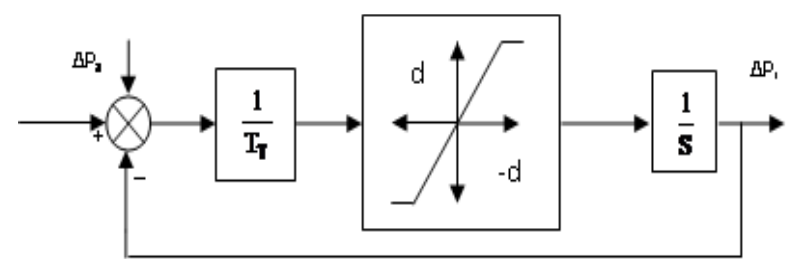

Figure11. Nonlinear turbine model with GRC

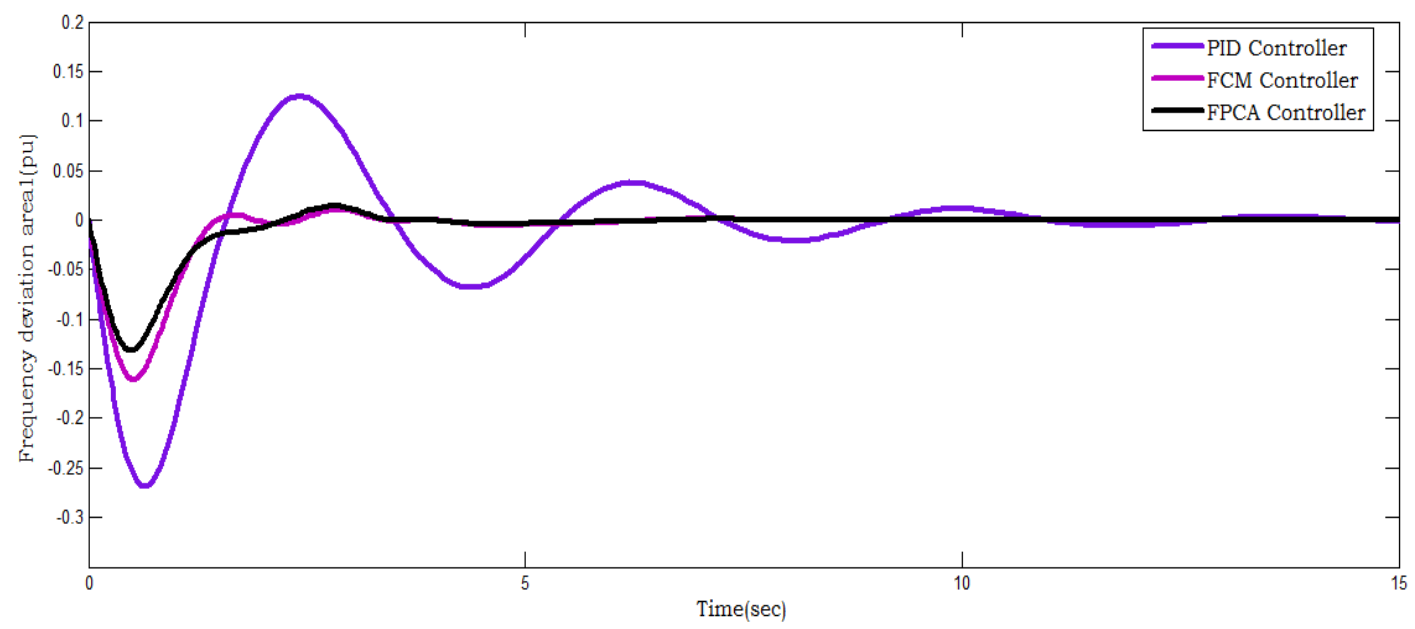

Figure12. Frequency deviation in area 1 including GRC with step increase in $\triangle \mathrm{PD} 1, \Delta \mathrm{PD} 2$ and $\Delta \mathrm{PD} 3$ 
International Journal of Fuzzy Logic Systems (IJFLS) Vol.6, No.1, January 2016

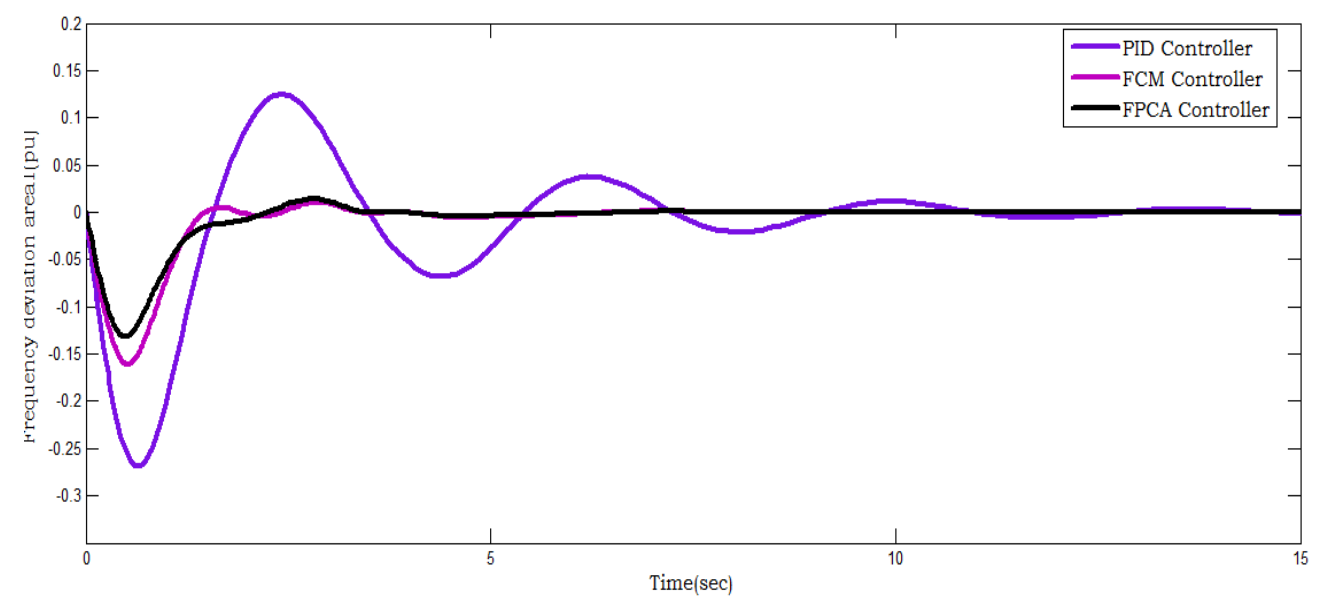

Figure 13.Frequency deviation in area 2 including GRC with step increase in $\Delta \mathrm{PD} 1, \Delta \mathrm{PD} 2$ and $\Delta \mathrm{PD} 3$

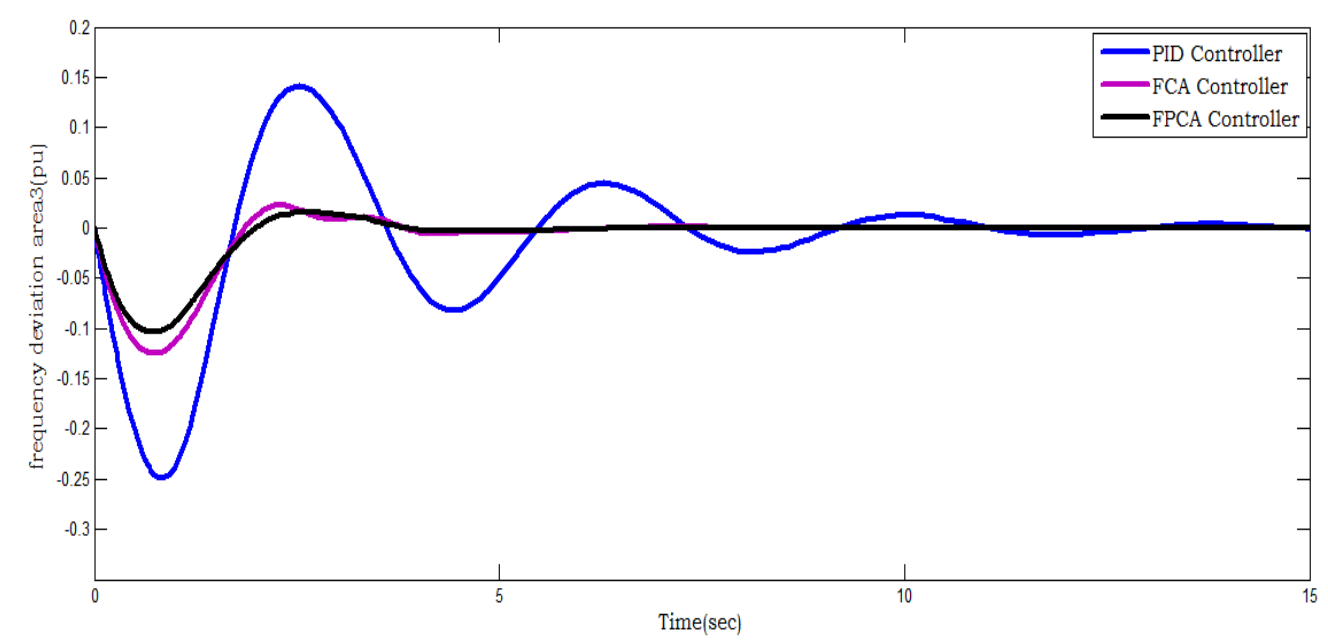

Fig.14.Frequency deviation in area 3 including GRC with step increase in $\Delta \mathrm{P}_{\mathrm{D} 1}, \Delta \mathrm{P}_{\mathrm{D} 2}$ and $\Delta \mathrm{P}_{\mathrm{D} 3}$

\section{Case3:}

In this case the contract same as the case1.Also load demand for each DISCO is considered $0.1 \mathrm{pu}$, the bounded variable step load changes in the a load change as un contracted demand in area 1, area2 and area 3 (Fig15) appears in all control areas where

$$
-0.07(p u) \leq \Delta P d i \leq 0.07(p u)
$$

The purposed for this toward check the robustness load variations up $40 \%$ deregulated power system of above It can be observed that the proposed FPCA controller with minimum rule base has better performance in all responses with respect to overshoot, undershoot and settling time and robustness when compared to FCM controller and PID controller. against parametric uncertainties and variable large load changes. $\Delta \mathrm{pd} 1, \Delta \mathrm{pd} 2$ and $\Delta \mathrm{pd} 3$ (fig22-25) The results in this case are given in Fig 16-18 
International Journal of Fuzzy Logic Systems (IJFLS) Vol.6, No.1, January 2016

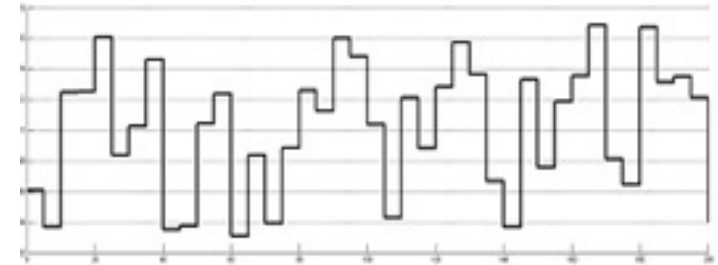

|al

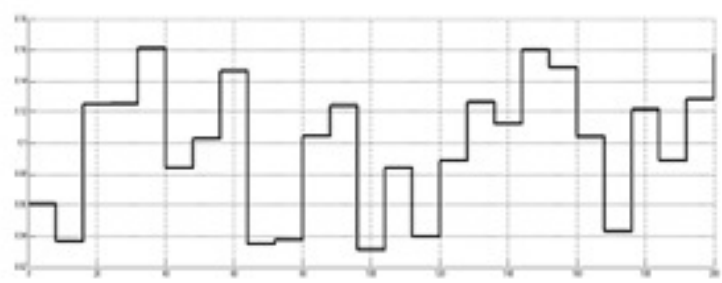

(b)
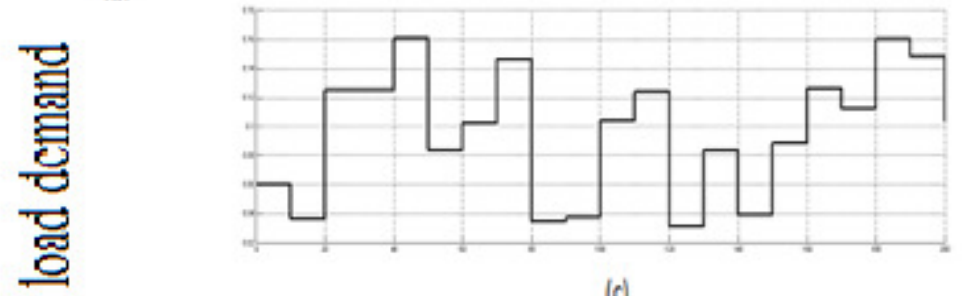

(c)

Time(sec)

Figure 15. Random load for three control areas in $\Delta \mathrm{P}_{\mathrm{D} 1}, \Delta \mathrm{P}_{\mathrm{D} 2}, \Delta \mathrm{P}_{\mathrm{D} 3}$

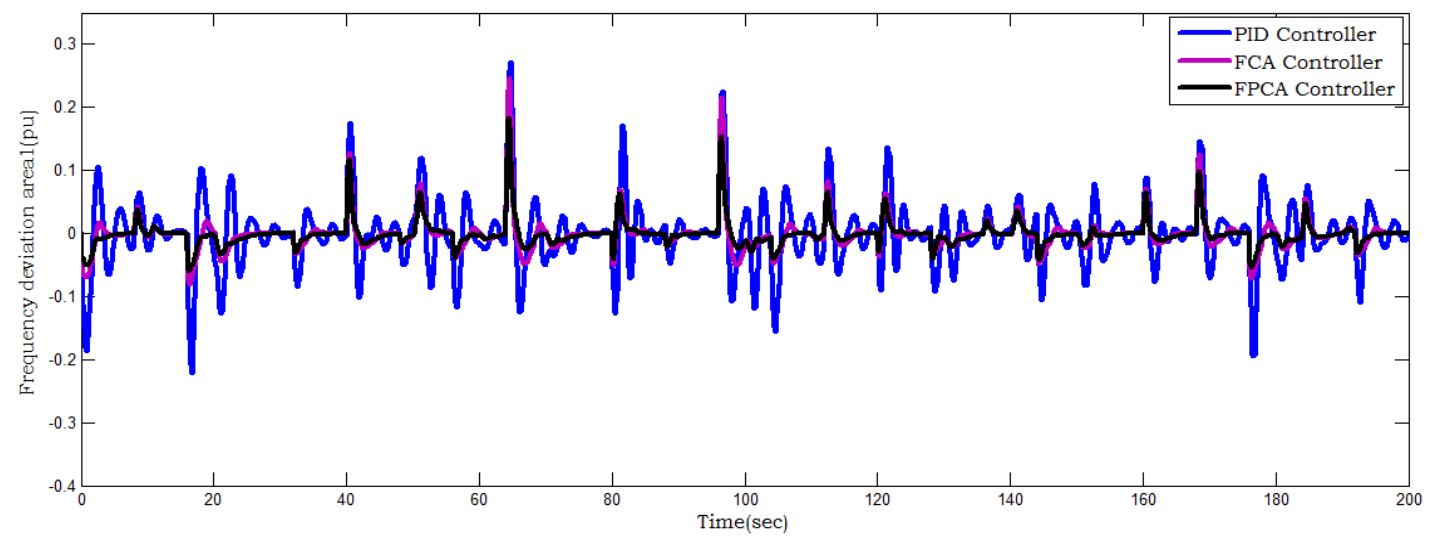

Figure 16. Frequency deviation in area1 with Random loading $\Delta \mathrm{P}_{\mathrm{D} 1}, \Delta \mathrm{P}_{\mathrm{D} 2}$ and $\Delta \mathrm{P}_{\mathrm{D} 3}$

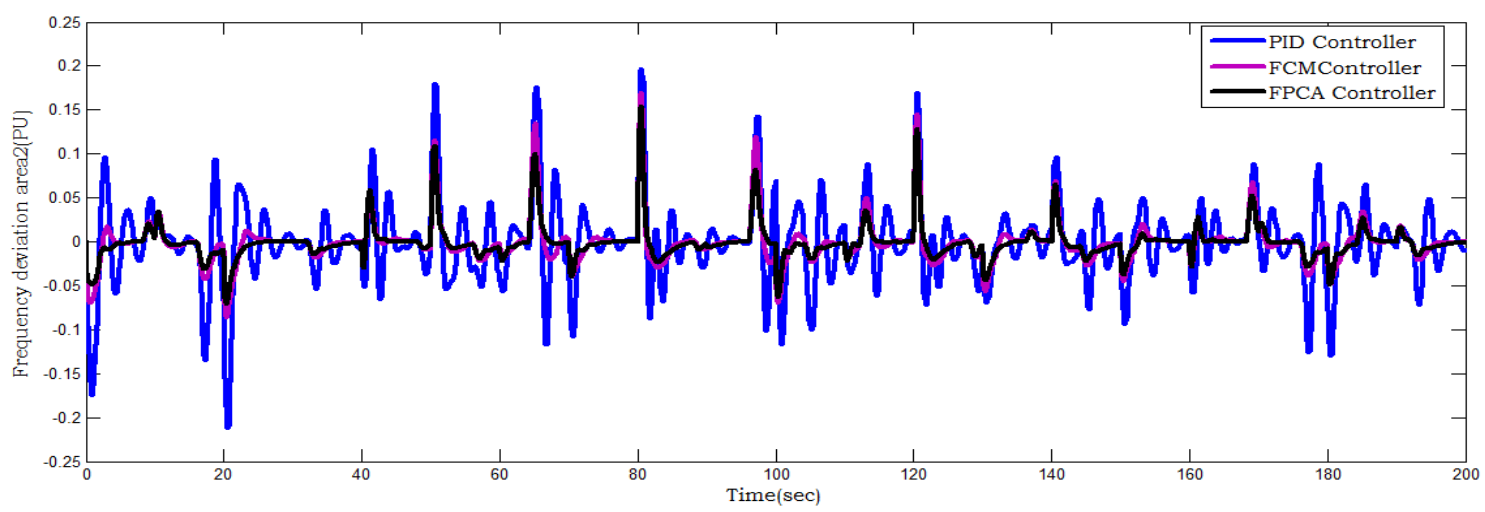

Fig.17.Frequency deviation in area2 with Random loading $\Delta \mathrm{PD} 1, \Delta \mathrm{PD} 2$ and $\Delta \mathrm{PD} 3$ 
International Journal of Fuzzy Logic Systems (IJFLS) Vol.6, No.1, January 2016

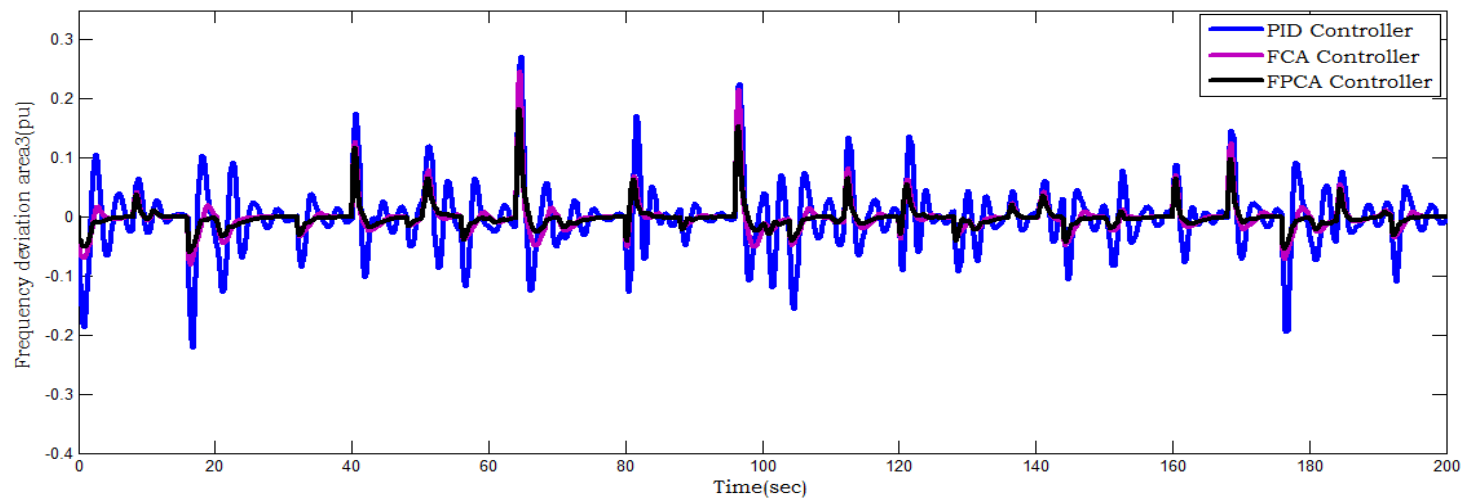

Figure 18.Frequency deviation in area3 with Random loading $\Delta \mathrm{P}_{\mathrm{D} 1}, \Delta \mathrm{P}_{\mathrm{D} 2}$ and $\Delta \mathrm{P}_{\mathrm{D} 3}$

Table.3. Numerical analysis of above results

\begin{tabular}{|c|c|c|c|c|}
\hline Case & Controller & $\begin{array}{l}\text { Settling } \\
\text { Time(sec) }\end{array}$ & $\begin{array}{l}\text { Maximum } \\
\text { overshoot }\end{array}$ & $\begin{array}{l}\text { Under } \\
\text { overshoot }\end{array}$ \\
\hline \multirow[t]{3}{*}{$1(\Delta \mathrm{f} 1)$} & PID & 13 & 0.09 & 0.21 \\
\hline & FCM & 5 & 0.03 & 0.13 \\
\hline & FPCA & 4.5 & 0.02 & 0.11 \\
\hline \multirow[t]{3}{*}{$1(\Delta \mathrm{f} 2)$} & PID & 13 & 0.02 & 0.19 \\
\hline & FCM & 5.0 & 0.03 & 0.13 \\
\hline & FPCA & 4.5 & 0.02 & 0.11 \\
\hline \multirow[t]{3}{*}{$1(\Delta \mathrm{f} 3)$} & PID & 13 & 0.1 & 0.20 \\
\hline & FCM & 5 & 0.03 & 0.13 \\
\hline & FPCA & 4.5 & 0.02 & 0.11 \\
\hline \multirow[t]{3}{*}{$2(\Delta \mathrm{f} 1)$} & PID & 15 & 0.12 & .0 .24 \\
\hline & FCM & 5.3 & 0.05 & 0.14 \\
\hline & FPCA & 4.8 & 0.03 & 0.11 \\
\hline \multirow[t]{3}{*}{$2(\Delta \mathrm{f} 2)$} & PID & 15 & 0.12 & 0.24 \\
\hline & FCM & 5.3 & 0.04 & 0.14 \\
\hline & FPCA & 4.8 & 0.02 & 0.11 \\
\hline \multirow[t]{3}{*}{$2(\Delta \mathrm{f} 3)$} & PID & 15 & 0.11 & 0.23 \\
\hline & FCM & 5.1 & 0.05 & 0.15 \\
\hline & FPCA & 4.5 & 0.02 & 0.11 \\
\hline \multirow[t]{3}{*}{$3(\Delta \mathrm{f} 1)$} & PID & - & 23.41 & 26.26 \\
\hline & FCM & - & 17.17 & 16.6 \\
\hline & FPCA & - & 15.00 & 6.0 \\
\hline \multirow[t]{3}{*}{$3(\Delta \mathrm{f} 2)$} & PID & - & 24.38 & 18.78 \\
\hline & FCM & - & 15.08 & 14.57 \\
\hline & FPCA & - & 13.00 & 12.45 \\
\hline \multirow[t]{3}{*}{$3(\Delta \mathrm{f} 3)$} & PID & - & 31.82 & 31.17 \\
\hline & FCM & - & 24.1 & 20.63 \\
\hline & FPCA & - & 20.0 & 18.15 \\
\hline
\end{tabular}




\section{CONCLUSION}

In this paper a new controller Fuzzy Principal component analysis controller (FPCA) is design minimization of fuzzy rules for load frequency control deregulated power system. The minimum rules indentify by using principal component analysis locus and identify the clusters centers in hyper-plane and converts in to the rules for FPCA controller. The FPCA controller tested for load frequency three area deregulated power system with minimum rules better performance of FCM Controller. The simulation results are signify the FPCA Controller is good performance in all operating conditions and mainly consider settling time, percentage of maximum over shoot, and under shoot. The numerical analysis show that FPCA Controller as better performance as compare to FCM and PID Controller.

\section{REFERENCES}

[1] G.T. C. Sekhar ,Rabindra Kumar Sahu and P.Sidhartha “ AGC of a multi-area power system under deregulated environment using redox flow batteries and interline power flow controller" International Journal of Engineering Science and Technology Elsevier, 2015 ,vol.18,No.1, pp.555-578

[2] Chandan Kumar Shiva and V. Mukherjee, "A novel quasi-oppositional harmony search algorithm for AGC optimization of three-area multi-unit power system after deregulation", Int. Journal of Engineering Science and Technology, Elsevier,2015, vol.18, pp.1-25

[3] Asadur Rahman, Lalit Chandra Saikia, Nidul Sinha "Load frequency control of a hydro thermal system under deregulated environment using biogeography-based optimised three degree-offreedom integral-derivative controller" IET Generation .Transmission Distribution,2015, vol.6.pp2284-2293

[4] P.K. Hota , Banaja Mohanty “Automatic generation control of multi source power generation under deregulated environment" International Journal of Electrical Power and Energy Systems 2016, vol.75:1 pp.205-214

[5] Hailin Li "Accurate and efficient classification based on common principal components analysis for multivariate time series" International Journal of Neurocomputing, Elsevier,2016, vol.171 pp.744753

[6] Y. Arya , Narendra Kumar, "AGC of a multi-area multi-source hydrothermal power system interconnected via AC/DC parallel links under deregulated environment" International Journal of Electrical Power and Energy Systems,2016, vol.75:1 pp.127-138

[7] K.P.Singh Parmar, S.Majhi, D.P.Kothari, 'LFC of interconnected power system with multisource power generation in deregulated power environment', International Journal of Electrical

Power and Energy Systems ,2014, vol.57 pp.277-286

[8] Factemeh Daneshfar,“ Intelligent Load Frequency Control in Deregulated Environment Continuous valued input, Extended classifier system approach”, IET Generation .Transmission \&.Distribution, 2013, vol. 7 pp551-559

[9] Javad Sadeh, Elyas Rakhshani, "Multi-Area Load Frequency Control in Deregulated Power System using Optimal Output Feedback Method”, European Electricity market, 2008, 5th EEE International Conference.

[10] E.Anderson and et al. "Principal component analysis the society for Industrial and Applied Mathematics", 1989, third edition

[11] D.H.Jeong and et al. "Understanding Principal Component analysis a visual analytics Tool", IEEE trans. pattern anal. Machine Intell,1995, vol.2,pp.773-781

[12] Elyas Rakhshani, Javad Sadeh, "Practical viewpoints on load frequency control problem in a deregulated power system", International Journal on Energy Conversion and management 51 (2010) pp. 1148-1156. 
International Journal of Fuzzy Logic Systems (IJFLS) Vol.6, No.1, January 2016

[13] Sudha K.R, Butchiraju Y, Chandra Sekar A, 'Fuzzy C-Means clustering for robust decentralized load frequency control of interconnected power system with Generation Rate Constraint', International Journal of Electrical Power and Energy Systems (2012), vol.37:1 pp.58-66

[14] Sudha KR, Vijaya Santhi R. "Robust decentralized load frequency control of interconnected power system with Generation Rate Constraint using Type-2 fuzzy approach". Int J Electr Power Energy Syst 2011;33:699-707.

[15] V.S.Vakula, K.R.Sudha "Design of differential evolution algorithm based robust fuzzy logic power system stabilizer using minimum rule base", IET Gener. Trans.Distrib.(2011) pp1-12

[16] V Donde, A Pai and Hiskens, , "Simulation and Optimization in an AGC System after Deregulation" IEEE Trans on Power Systems, vol 16 no 3,pp481-489,Aug 2001.

[17] Sudha KR, Vijaya Santhi R. Load frequency control of interconnected reheat thermal system using Type-2 fuzzy system including SMES units Int J Electr Power Energy Syst 2012;43:1383-1392

[18] F. Liu, Y.H. Song, J. Ma, Q. Lu, "Optimal Load Frequency Control in the Restructured Power Systems", IEE Proc. Gener. Transm. Distrib. Vol. 15, No. 1, pp.87-95, 2003.

[19] H. Shayeghi, H.A. Shayanfar, A. Jalili, M. Khazaraee, "Area Load Frequency Control Using Fuzzy PID Type Controller in a Restructured Power System", International Conference on Artificial Intelligence, Las Vegas, Nevada, USA, pp. 344-50, June 27-30, 2005.

[20] T.C. Yang, H. Cimon, Q.M. Zhu, "Decentralized Load- Frequency Control Design Based on Structured Singular Values", IEE Proc. Genre. Transm. Dstrib., Vol. 145, No.1, pp. 7-14, January 1998.

[21] H.A. Shayanfar, H. Shayeghi, A. Jalili, M. Sivandian, "A Genetic Algorithm Based AGC of a Restructured Power System”, International Conference on Artificial Intelligence, Las Vegas, Nevada, USA, pp. 237-240, June 2006.

[22] A.P. Sakis Meliopoulos, George J. Cokkinides, A.G. Bakirtzis, 'Load-frequency control service in a deregulated environment' Decision Support Systems $24 ; 1999.243-250$

[23] H. Shayeghi, H.A. Shayanfar, O.P. Malik, "Robust Decentralized Neural Networks Based LFC in a Deregulated Power System”, Electric Power System Research, Vol. 77, No. 3, pp. 241-251, 2007.

[24] E. Rashedi, H. Nezamabadi-pour, S. Saryazdi, "Filter Modeling Using Gravitational Search Algorithm", Engineering Applications of Artificial Intelligence, Vol. 24, No. 1, pp. 117-122, 2010.

[25] P. Bhatt, R. Roy, S.P. Ghoshal, "Optimized Multi Area AGC Simulation in Restructured Power Systems", Electrical Power and Energy Systems, Vol. 32, pp. 311-322, 2010.

[26] T. Hiyama, and Sameshima.T., "Fuzzy Logic Control Scheme for On-Line Stabilization of MultiMachine Power System", Fuzzy Sets and systems, Vol. 39, pp. 181-194, 1991.

[27] K.A. El-Metwally, "A Fuzzy Logic - Based PID For Power System Stabilization" Electric Power Components and systems, Vol. 29, pp. 659-669, 2001.

[28] Srikanth NV, Vinod Kumar DM. "Investigation of stability of fuzzy logic based power system stabilizer using phase-plane analysis". National power systems conference, NPSC; 2004. p. 408-411.

[29] Bezdek JC. "Pattern recognition with fuzzy objective function algorithms". NY: Plenum Press; 1981.

[30] Ying H. Deriving analytical input-output relationship for fuzzy controllers using arbitrary input fuzzy sets and Zadeh fuzzy and operator. IEEE Trans Fuzzy Syst 2006;14:654-662 